\title{
- Associativismo dos Trabalhadores em Educação e suas lutas em torno da Educação de Jovens e Adultos
}

\author{
Marco Mello' \\ ' Historiador. Mestre em Educação (UFRGS). Professor e Coordenador Pedagógico na Rede Municipal de Ensino de Porto \\ Alegre - RS. E-mail: marcomello2013@gmail.com
}

Recebido em: 14 jan. 2019. Aceito em: 03 mar. 2019 DOI: http://dx.doi.org/10.21674/2448-0479.52.198-207

\section{Resumo}

Este artigo é parte de uma pesquisa mais ampla, realizada junto ao PPG/EDU/UFRGS, que situa o Associativismo e o Sindicalismo Docente como sujeitos fundamentais na afirmação de uma identidade e pertença coletiva dos trabalhadores em educação e, ao mesmo tempo, campo de estudos para a análise das políticas educacionais. No texto é destacado o papel da ATEMPA (Associação dos Trabalhadores em Educação do Município de Porto Alegre) em relação às políticas educacionais e curriculares da Educação de Jovens e Adultos junto à Secretaria Municipal de Educação no período 2005-2018. Conclui-se afirmando o papel estratégico da Associação dos Trabalhadores, na manutenção da oferta da modalidade. Ao mesmo tempo são identificadas novas ameaças de desmonte da EJA e o agravamento do cenário sob uma hegemonia conservadora multiescalar, por efeito de um projeto de precarização e mercantilização da educação pública e de ataque à autonomia docente, o que coloca em risco os marcos legais e os avanços políticos-pedagógicos e programáticos construídos ao longo das duas últimas décadas em relação à modalidade.

Palavras-chave: Associativismo e Sindicalismo Docente. Associação dos Trabalhadores em Educação do Município de Porto Alegre. Educação de Jovens e Adultos. Políticas Curriculares.

\begin{abstract}
This paper is part of a mainresearch carried out together with the PPG / EDU / UFRGS, which places Associativism and Teaching Syndicalism as fundamental subjects in the affirmation of an identity and collective belonging of workers in education and, at the same time, studies for the analysis of educational policies. The paper highlights the role of ATEMPA (Association of Workers in Education of the Municipality of Porto Alegre) in relation to the educational policies and curriculum of Youth and Adult Education at the Municipal Department of Education in the period 2005-2018. It concludes affirming the strategic role of the Workers' Association, in maintaining the offer of the modality. At the same time, new threats of dismantling of the EJA and the aggravation of the scenario under a multiscale conservative hegemony are identified, under a project of precarization and mercantilization of the public education and attack to the autonomy of the teacher; which puts at risk the legal frameworks and the politicalpedagogical and programmatic advances built over the last two decades in relation to the modality.
\end{abstract}

Keywords: Associativism and Teachers Union. Association of Workers in Education of the Municipality of Porto Alegre. Youth and Adult Education. Curricular Policies. 


\section{Introdução}

\section{Associativismo e Sindicalismo Docente}

Há décadas, no Brasil e na América Latina, os trabalhadores em educação têm protagonizado importantes lutas em prol da afirmação de direitos por salários dignos, por melhores condições de trabalho e carreira, pela defesa da escola pública, gratuita, com qualidade social, bem como contra governos autoritários e reformas neoliberais e privatistas. Em nosso país são centenas de sindicatos, associações e federações de trabalhadores em educação construídos como ferramentas de luta social e de afirmação de uma identidade e pertença coletiva.

Desde esse protagonismo coletivo um novo campo de estudos vem se afirmando e dá largos passos em vias de consolidação, em um entrecruzamento de estudos no âmbito da história, da sociologia e da educação. Trata-se do Associativismo e do Sindicalismo docente (GINDIN, FERREIRA; DAL ROSSO, 20I3; ALMEIDA; FERREIRA JR., 20I5).

Apesar do número significativo de pesquisas no âmbito acadêmico acerca da organização e das lutas gerais do sindicalismo docente, ainda são em número relativamente pequeno os trabalhos que investigam as reações às reformas curriculares gestadas e implementadas nas redes públicas no cenário recente. E são quase inexistentes pesquisas que tematizem a relação entre o sindicalismo docente e a modalidade da Educação de Jovens e Adultos.

Neste artigo, socializo algumas conclusões advindas de uma experiência de pesquisa (MELLO, 2015a) que destacou o papel da ATEMPA (Associação dos Trabalhadores em Educação do Município de Porto Alegre), em relação às políticas curriculares da Secretaria Municipal de Educação no período de 2005 a 2014 . A delimitação espaço-temporal da pesquisa se justificou por ser um período de gestões trabalhistas na condução das políticas educacionais que se seguiram a gestões sucessivas da Frente Popular (I 989-2004), nas quais a capital gaúcha foi administrada por uma coalizão de partidos de esquerda sob a condução do Partido dos Trabalhadores (PT), quando a Rede Municipal de Ensino vivenciou profundas transformações na sua gestão e particularmente em relação a processos de reorganização curricular de cunho progressista com um exemplo paradigmático de gestão local participativa, inclusiva e cidadã (GANDIN, 20I I).

Visto desde outra escala, no mesmo período, o cenário nacional foi caracterizado pela incidência de políticas educacionais sob as gestões Lula da Silva e Dilma Rousseff. Sob esse pano de fundo, procurei perceber, através da investigação, como os trabalhadores em educação e suas organizações se posicionaram nesse novo período histórico. Neste artigo atualizo o debate, com a análise do final do ciclo trabalhista (20I52016), e trago elementos empíricos para uma análise preliminar das políticas levadas a cabo pela gestão do PSDB na capital gaúcha na primeira fase do seu governo (2017-20।8).

\section{Materiais e métodos}

Os procedimentos metodológicos privilegiaram uma abordagem de caráter hermenêutico-dialético e os instrumentos de pesquisa utilizados combinaram uma ampla análise documental com a realização de entrevistas a dirigentes do movimento associativo-sindical e a ativistas em espaços de representação institucional, além de observação participante.

\section{Resultados e Discussão}

\section{ATEMPA: História e perfil organizativo}

Foi a partir de uma forte mobilização da sociedade civil em torno das lutas pelas liberdades democráticas do país, ainda nos estertores de uma ditadura civil-militar, que nascem as primeiras tentativas e experiências de reorganização e lutas dos educadores da capital gaúcha (1977-1988), em um núcleo dos municipários que se reunia com alguma regularidade no CPERS-Sindicato. Em agosto de 1985 é revitalizada a APMPA - Associação dos Professores Municipais de Porto Alegre, que teve uma primeira fase de existência (1964-1968) no contexto da ditadura civil-militar e que, em 1992, se transformaria em ATEMPA.

A ATEMPA, como intelectual coletivo, é resultado do empenho de ativistas orgânicos de diferentes gerações e tradições de esquerda que fizeram dela um espaço de organização e reconstrução da identidade da categoria dos trabalhadores em educação. Sua existência marcou um novo ciclo de lutas e nela os 
trabalhadores em educação realizaram o diálogo e a tensão com os gestores locais, desde a recuperação e ressignificação do legado de sua antecessora, a APMPA.

A Associação dos Trabalhadores em Educação tem sido protagonista, ao longo de sua existência, de lutas específicas para os trabalhadores em educação, como o grande movimento em prol do Plano de Carreira do Magistério transformado na Lei Municipal 6I5I/88. Ao longo da sua história a Associação participou ativamente da discussão das políticas educacionais protagonizando, juntamente com a comunidade escolar, a implementação da Gestão Democrática na RME, apesar de um papel subordinado em grande parte do período em que o Partido dos Trabalhadores esteve à frente do governo municipal.

Como organização, a ATEMPA evidencia um forte enraizamento e preservação de valores caros às organizações dos trabalhadores: uma ampla adesão de associados, organização por local de trabalho, não profissionalização dos dirigentes, sustentação espontânea das atividades, instâncias democráticas de decisão, direção horizontalizada e permanente mobilização, seja em torno de pautas clássicas na melhoria das condições de trabalho e valorização profissional, seja em torno de questões de ordem pedagógica (MELLO, 20 I5b).

\section{Rede Municipal de Educação e os primórdios da EJA nas gestões petistas}

A Rede Municipal de Educação de Porto Alegre possui 99 escolas, sendo 48 de Ensino Fundamental, nas quais atende 40.077 alunos. Desses, 6.233 são matriculados na EJA, com a oferta presencial em duas escolas da modalidade e outras $31 \mathrm{com}$ turmas no período noturno. A rede possui 4 Escolas Especiais, 2 escolas de Ensino Médio e Educação Profissional, 7 jardins de praça e 35 escolas infantis. São 4.077 professores da rede própria (366 atuando exclusiva ou concomitantemente na EJA), além dos funcionários de apoio, entre concursados, celetistas e terceirizados. Além disso, 225 creches comunitárias são conveniadas com a administração local, e recebem recursos e assessoria do poder público para seu funcionamento (PMPA, 2016).

Depois de 16 anos à frente do governo Municipal sob as gestões petistas (1989-2004), justamente em um momento de cercamento e hegemonia das políticas neoliberais em escala global, o saldo da EJA foi - em que pese não haver fonte de financiamento específico para a modalidade à época - o da existência de uma rede construída em 37 escolas na periferia da cidade, algo inexistente até então, uma proposta político-pedagógica e de organização curricular de caráter acentuadamente progressista, professores concursados e formação sistemática em serviço, com assessoria especifica para a EJA.

Em Porto Alegre, o compromisso com a oferta adequada da EJA veio sendo discutido e implantado desde 1989. Nesse processo, consolidou-se em 1996 a proposta pedagógica por meio das Totalidades de Conhecimento, fortemente embasada no paradigma da Educação Popular, orientada por uma concepção dialógica e interdisciplinar (PMPA, 1996). Já a avaliação assume um caráter processual e emancipatório, passando a ser coletiva global e permanente.

\section{Gestões trabalhistas na SMED (2005-2016): um sopro sobre as brasas}

Apesar de apregoar a defesa apaixonada do papel da Educação em suas elaborações e programas governamentais, o PDT - Partido Democrático Trabalhista - efetivamente não construiu uma elaboração clara e precisa em relação à sua principal bandeira de luta. Foi possível perceber a inexistência de um projeto educacional organizador e claro por parte dos gestores para o conjunto da RME, no qual se pudessem identificar as intencionalidades e os fundamentos políticos, epistemológicos e pedagógicos da concepção de organização curricular e sua operacionalização.

Não bastasse, houve a torção da Gestão Democrática no âmbito da escola e do Sistema Municipal de Ensino, com a adoção de práticas verticalizadas, com uma forte relação de cobrança e coerção das direções de escolas, dos conselheiros escolares e conselheiros municipais de educação, com traços acentuados de autoritarismo e direitivismo.

Nas gestões pedetistas à frente da SMED, em especial a partir de 2009, muitas foram as tentativas de desmonte da Educação de Jovens e Adultos, através do fechamento de turmas, remanejos de professores, esvaziamento das formações e busca da desconstituição da proposta curricular de referência, por Totalidades de Conhecimento (MELLO, 20I5a).

A tônica das posições assumidas pela ATEMPA no período 2005 a 2012, em resposta às gestões trabaIhistas, revelou um duplo movimento: de defesa das conquistas obtidas pela categoria na década de 1990 e institucionalizadas no período das Administrações Populares e de ausência de formulações críticas em torno 
das interferências gerencialistas nas políticas curriculares, que acabaram assumindo uma feição própria no contexto local. No período de 2013 a 2016 a direção que esteve na condução da ATEMPA, imprimiu um movimento mais vigoroso e trouxe a defesa da modalidade para um primeiro plano das agendas de lutas.

Em que pese as limitações percebidas, a Educação de Jovens e Adultos desde o período foi uma das políticas curriculares vigorosamente defendidas pela ATEMPA desde a base das escolas, na defesa da manutenção da modalidade, do projeto pedagógico das Totalidades de Conhecimento, regulamentação legal e representação institucional, com vitórias organizativas significativas no período, e que destoaram da condução geral da direção da ATEMPA por expressar posições distintas dos intelectuais orgânicos que nesse espaço atuaram, orientados por perspectivas contra-hegemônicas (MELLO, 20 I5a, 20 I5b).

\section{Tucanos sob o céu porto-alegrense}

Despois de três gestões consecutivas que tiveram uma coalizão alicerçada no antipetismo, que agrupou, tanto os tradicionais partidos conservadores (PMDB, PP, PSDB, PFL) como os trabalhistas (PTB e PDT) e os verdes (PV), além de outros partidos de menor expressão (PAN, PHS, PSDC, PRTB), as eleições municipais de 2016 evidenciaram a cisão do bloco, o isolamento do PDT e a vitória do PSDB, em aliança com o PP, PMB, PTC e PV com o apoio decisivo do PTB no segundo turno das eleições.

Ao longo dos primeiros dois anos, as principais ações do governo Marchezan Jr. (PSDB) têm sido marcadas pelo deslocamento, interferência e esvaziamento das instâncias democráticas (Conselhos de Direito, Orçamento Participativo, etc.) - fortalecendo, desse modo, o gestor e os grandes conglomerados econômicos - e o desmonte e sucateamento dos serviços públicos, desrespeito à população e aos servidores, com ataques às condições de trabalho e à carreira dos trabalhadores. Sob uma alegada "crise das finanças do município", que vem sendo contestada pelos próprios trabalhadores e pelo Tribunal de Contas do Estado, o que se identifica é um forte assédio moral e criminalização dos movimentos dos trabalhadores municipários. Além disso, o congelamento, atraso e parcelamento de salários, a revogação de regimes especiais de trabalho, a ampliação das parcerias público-privada em várias áreas de infraestrutura (SIMPA, 20I8; ATEMPA, 20I7d, 20I8), levaram a um permanente enfrentamento com o governo e a realização de grandes greves da categoria.

$\mathrm{Na}$ Rede Municipal de Ensino de Porto Alegre as políticas levadas a cabo pelo Prefeito Marchezan Jr. e pelo Secretário Adriano Neves têm sido marcadas, na ótica dos trabalhadores em educação, pelo autoritarismo e truculência, desconsideração dos marcos legais construídos, falta de transparência na aplicação dos recursos do FUNDEB e esvaziamento da proposta pedagógica. Mudanças têm sido largamente criticadas pela Associação dos Trabalhadores, tais como: fim da política de formação continuada e em serviço, falta de recursos humanos nas escolas, fim das reuniões pedagógicas, proibição do planejamento coletivo e individual do professor fora da escola; restrição da Gestão Democrática, imposição do calendário escolar às comunidades, fechamento de projetos culturais inovadores nas escolas, precarização das condições de trabalho dos professores com a falta de estrutura, ambiente e equipamentos para um planejamento adequado, determinação de nova rotina escolar que diminui tempo de aula dos alunos, restrições ao consumo da merenda escolar, demissão de funcionários dos serviços de alimentação escolar, portaria e limpeza, intensificação do trabalho docente (ATEMPA, 20 I7b, 20 I8a).

Recentemente, mais uma ação nefasta foi perpetrada, com a perseguição política à diretoria da entidade, e a todos associados da Atempa, com a convocação de diretores eleitos para o retorno imediato às escolas, inviabilizando-os de atuarem como representantes da categoria (ATEMPA, 20I8b).

\section{Desconstruções das Políticas para a Educação de Jovens e Adultos}

Em uma análise do Programa de Governo do então candidato do PSDB à prefeitura de Porto Alegre, em 2016, apresentado junto ao TSE no registro de sua candidatura, percebe-se que tipo de educação o partido almejava para o município. De cerca de quinze páginas de propostas vagas, o documento reserva menos que uma página para a educação, em que não há um cuidado de definir quais são suas concepções e qual é seu o compromisso com a área (GONÇALVES; MELLO; FERREIRA, 20I8). Sobre a EJA nenhuma palavra.

Relatório de monitoramento da própria Secretaria Municipal de Educação com o Fórum Municipal de Educação' atesta que as metas e diretrizes do Plano Municipal de Educação da capital gaúcha (20I5-2025)

\footnotetext{
' O Fórum Municipal de Educação - FME/PoA é integrado por representações de órgãos, movimentos, instituições e entidades ligados ao campo da Educação no território da cidade de Porto Alegre e tem, entre outras finalidades, o monitoramento do Plano Municipal de Educação - PME/PoA.
} 
- muitas delas progressistas em relação à EJA, têm sido solenemente ignoradas pelos gestores de plantão, e praticamente não há o que comemorar (PMPA, FME/POA, 20I7).

Especificamente a política de descaso com a modalidade da EJA na gestão recente tem se expressado através de decisão arbitrária de Secretaria Municipal de Educação, sem qualquer diálogo com as comunidades escolares, de diminuição da oferta da EJA no município, através do fechamento de turmas, centralização das matrículas em uma escola-polo, não nomeação de professores para os cargos vagos, fim das reuniões mensais de coordenação da EJA, inexistências de formações em serviços destinadas aos educadores, extinção de projetos voltados à modalidade, destituição da (já pequeníssima) equipe de assessoria de EJA existente, bem como da Coordenação da Política de EJA na SMED.

Essas atitudes arbitrárias tomadas pelos gestores municipais negam frontalmente o direito à educação, garantida pela Constituição Federal de 1988, a jovens, adultos e idosos. Além de negligenciar a LDBEN, o ECA e contrariar as metas 8 e 9 do PNE, que definem estratégias para ampliação da escolaridade da população brasileira e a redução das desigualdades étnicos-raciais, de gênero e geracionais.

É imperioso reconhecer uma verdadeira obstinação dos gestores em mitigar a própria existência da modalidade. Todavia, contradições são percebidas. O cotejamento entre a oferta e a demanda potencial da EJA no RS tem tido importante contribuição a partir das pesquisas de Alves, Comerlato e Sant'anna (2017 e 2018) com dados concretos e oriundos do IBGE/Censo 2010. Em Porto Alegre, são 25.979 pessoas acima de 15 anos que não sabem ler e escrever. Para o Ensino Fundamental, em Porto Alegre, são mais de 298. 156 pessoas que não completaram esta etapa da educação básica. Tais dados evidenciam que, nas palavras dos autores: "É responsabilidade do Poder Público municipal, conforme LDB recenseamento anual de jovens e adultos e maior publicização das chamadas públicas, a fim de converter a demanda potencial pela EJA em efetivos estudantes da modalidade na rede de atendimento já existente na cidade" (ALVES; COMRLATO; SANT'ANNA, 2017, p.45).

$O$ ponto de maior tensão entre gestores e trabalhadores da EJA e comunidades escolares foi a tentativa da SMED de concentração de todas as matrículas da modalidade Educação de Jovens e Adultos no CMET Paulo Freire, escola de EJA próxima ao Centro Histórico, em 2017. As escolas foram impedidas de realizar matrículas de novos alunos na EJA, processo que passou a ser centralizado na SMED. A justificativa da Secretaria foi uma suposta baixa procura nas comunidades, mas efetivamente foi mais uma ação visando a progressiva centralização e esvaziamento de poder decisório das escolas e a redução da oferta da EJA. Depois de muita resistência e luta política a Secretaria de Educação voltou atrás e anulou o ato administrativo arbitrário.

Todavia, novos ataques visando o esvaziamento da oferta foram realizados pelos gestores, como a recente parceria da Prefeitura de Porto Alegre com o SESI/RS para a oferta de EJA na modalidade de Educação à Distância (80\% à distância e $20 \%$ presencial) para alunos maiores de 18 anos, já matriculados nas escolas nos anos finais (PMPA, 20 I8), em franco desacordo com a Resolução n 9/2009 do CME/PoA que no seu Art. 12 normatiza a "possibilidade de oferta de até $20 \%$ de carga anual com estudos não presenciais planejados [...]”. Na iniciativa da SMED, alinhada com o Decreto n 9.057/2017 que flexibiliza as regras da EaD, e sancionado pelo presidente Temer, o foco é a elevação da escolaridade, com preparação aligeirada e acrítica de mão de obra voltada para o mercado, através da terceirização da gestão e da docência.

No final do ano letivo de 2018, mais um ataque à EJA. Despacho da SMED determinou sumariamente o fechamento e unificação das turmas existentes para 2019, inicialmente em uma escola na zona norte da cidade, depois em outras cinco escolas, em distintas regióes da cidade e, finalmente, para toda a Rede. Tais medidas além de uma redução drástica da EJA nas escolas, não respeita as normativas do CME/PoA e as deliberações dos Conselhos Escolares, que afirmam a pertinência e o respeito às especificidades da oferta na modalidade. Com a efetivação da medida uma quantidade significativa de turmas serão fechadas, várias serão agrupadas, haverá diminuição do quadro de professores, o que, consequentemente, levará à precarização das aulas e a oferta de vagas. Segundo a ATEMPA (2018c), "o encaminhamento parece ser mais uma tentativa - equivocada - de resolver a falta crônica de professores nas aulas dos outros turnos".

A adesão ao novo gerencialismo educacional (BALL, 20I4; NEWMANN; CLARKE, 20I2), sob a condução de Marchezan Jr. tem claramente como direção a "escola mínima”, a partir da privatização do que é público e do ataque à autonomia docente. Nesta lógica, reduzir e, se possível, acabar com a oferta da EJA, passa a ser uma meta levada a cabo com obstinação. Afinal, é uma política deliberada para toda a Rede, destinada a sonegar, mais uma vez, o direito à Educação, sobretudo das populações periféricas, da juventude negra e em grande número de mulheres, jovens e idosas. $\mathrm{O}$ ataque sobre a $\mathrm{EJA}$, portanto, em uma rede pública, não 
é algo isolado e pontual, mas, parte de um projeto perverso mais amplo orientado pela lógica da mercantilização da educação (BANCO MUNDIAL, 20I7) na direção do Estado mínimo e privatista.

\section{Tempos difíceis... Exigem resistência e luta}

Instâncias como o Conselho Municipal de Educação têm reafirmado os direitos da EJA. O mesmo foi unânime em recomendar à SMED fortes medidas para assegurar a divulgação, matrícula e busca ativa da população potencial da EJA (CMED, 2017). Ou seja, não se trata tão somente de descaso dos gestores municipais, mas, de atos de ilegalidade impostos pela Secretaria Municipal de Educação e que se configuram como crimes de responsabilidade administrativa.

De modo similar, manifestações de apoio foram publicizadas por diversas instituições e instâncias da sociedade civil organizada, Universidades, Conselhos de Direitos e intelectuais, Sindicatos e Federações Nacionais de Trabalhadores, Entidades Estudantis, Associações de Pesquisadores, Fóruns de EJA, Movimentos Sociais e Populares - na unidade em prol da defesa da Educação de Jovens e Adultos na capital gaúcha e em contrariedade às medidas adotadas pela Secretaria Municipal de Educação de Porto Alegre.

É preciso lembrar que os educadores vêm, através da ATEMPA, desde há muito, pautando a necessidade do cumprimento das obrigações constitucionais do poder público municipal em relação à oferta, manutenção e qualificação da modalidade da EJA (ATEMPA, 20I3, 20I5, 2017, 20I7a, 20I7b; VIERO, 2008; MELLO, $2015 a$ ), tais como a chamada pública permanente, recenseamento da população potencial para a oferta, recursos humanos e infraestrutura adequada, formação permanente dos docentes e respeito à proposta político-pedagógica vigente.

Contudo, não subestimemos o desafio. No mais das vezes é no seio das próprias organizações e ferramentas de luta que a força da EJA tem de emergir em busca de espaço, em meio às pautas mais gerais, inclusive de educadores, pois as especificidades tendem a ficarem subsumidas sob o guarda-chuva das "lutas gerais" da categoria.

As respostas percebidas, em grande parte dos trabalhadores, têm sido a participação coletiva nos movimentos associativos e sindicais (ATEMPA, 20I7a, 2017c; MELLO, 20I5a; SIMPA, 2017), fortalecendo as pautas gerais e fazendo emergir a especificidade da Educação de Jovens e Adultos. Exemplos disso tem sido a manutenção das reuniões pedagógicas da EJA (ATEMPA, 2017c) e a realização de eventos de caráter formativo, organizados pelos próprios trabalhadores, nas redes regionais autogerida pelas escolas e na solidariedade entre aqueles que estão alinhados na resistência às políticas educacionais do Governo Marchezan Jr. Além do caráter de denúncia, é possível identificar a visibilidade de muitas experiências e práticas pedagógicas significativas desde a realidade das escolas (MELLO, GONÇALVES, WASZAK, 20 I6; MELLO, 20 I8; MELLO; MAYER; PAVANI, 20I8), reafirmando o compromisso em torno de uma educação crítica, dialógica e contra-hegemônica, decorridos 20 anos da morte de Paulo Freire, uma referência sempre presente na EJA.

No momento em que este artigo é escrito, o campo de tensões é esgarçado e somente novas pesquisas poderão identificar o destino da EJA e o papel do Associativismo e do Sindicalismo na correlação de forças na rede pública municipal. Recentemente, a ATEMPA desencadeou uma campanha pública e massiva através da confecção de banners, faixas e carta aberta às comunidades, além da gravação e veiculação nas redes sociais de depoimentos de professores, alunos e ex-alunos da EJA. A insígnia não poderia ser significativa "A EJA é um direito! A EJA é nossa! Campanha em defesa da EJA em Porto Alegre" (ATEMPA, 2018c).

A EJA pública continua a existir em Porto Alegre porque as comunidades escolares, os educadores e seus instrumentos de luta, parlamentares progressistas, a mantém de pé. Não resta dúvida que é preciso precisamos conjugar a qualidade do trabalho pedagógico como educadores nos espaços nos quais atuamos com a força da organização política - porque essa dimensão ganha projeção absoluta na conjuntura. $E$ foram muitas lutas nos últimos anos. Mesmo assim, três escolas tiveram determinado o fechamento da EJA pela SMED desde 2016.

\section{Considerações finais}

\section{Desafios no porvir...}

A burguesia vem operando na coalisão de um novo bloco histórico para aplicar reformas estruturais, restaurar a acumulação capitalista por meio da mercantilização de direitos sociais e tentar contornar a grave crise política e econômica. A partir do golpe político-midiático ao Estado democrático de direito, perpetrado 
em 2016, um governo ilegítimo impôs uma agenda conservadora no âmbito econômico-político-ideológico-cultural e a sociedade viu, atônita, um alinhamento às políticas neoliberais e privatistas, claramente orientadas na lógica do "ajuste fiscal", que atinge fortemente a educação, a saúde e a cultura e se estendem, através de alianças espúrias, para afirmar e difundir valores reacionários, xenófobos, de intolerância religiosa, de naturalização da violência, racistas, sexistas e misóginos.

Não é objeto deste artigo, mas é preciso reconhecer que, evidentemente, parte desse resultado é fruto das contradições do transformismo político e programático petista (COELHO, 20I2) e das gestões dos governos petistas em nível federal, que optaram por um sistema de alianças com a grande burguesia financeira, industrial e agrária na construção de um novo pacto social e um reformismo voltado para a manutenção do padrão de acumulação vigente; o que implica dizer que houve um amalgamento de interesses dentro do velho paradigma do consenso entre capital e trabalho (IASI, 20I2), no qual o PT se inseriu como sócio minoritário no novo bloco histórico dominante (GRAMSCI, 1982). Dentro desse esquema, a operação produzida pelo lulismo (AB'SABER, 20I I; SINGER, 20 I2; LEHER, 20 IOb) se recusou sistematicamente ao embate ideológico em uma perspectiva contra-hegemônica na direção de um projeto histórico alternativo ao existente.

Em que pese o necessário balanço crítico, perante o cenário atual de avanço ideológico da nova direita e do desmonte das políticas públicas educacionais progressistas duramente conquistadas nos últimos trinta anos, é preciso reafirmar direitos e conter a sanha destruidora dos representantes do capital que insistem em subordinar a educação à lógica neoliberal e mercantilista e amordaçá-la ideologicamente (FRIGOTTO, 20 I 7).

Como pontuam Di Pierro e Catelli Jr. (20I7), um dos grandes desafios percebidos diz respeito ao financiamento da EJA, e ela pode ser medida pela queda vertiginosa das matrículas em escala nacional, a redução de vagas dos programas de alfabetização, de elevação de escolaridade e de qualificação profissional. Situação essa agravada pela crise econômica e aprovação da Emenda Constitucional n. 95/20l6, que fixou um teto de gastos públicos, o que significa restrição de recursos para a Educação e Saúde, o que, para alguns analistas, como Amaral (2016), pode significar a "morte" do PNE 20I4-2024.

A defesa do direito à Educação de Jovens e Adultos como política pública, gratuita, com qualidade social, exige necessariamente o esforço de unidade entre os trabalhadores/as da modalidade, pesquisadores, intelectuais e movimentos sociais e populares progressistas na defesa do direito à educação e da própria sobrevivência da EJA. Esse é o papel dos educadores críticos e progressistas.

As arenas da disputa de projetos em cursos e a correlação de forças desigual na conjuntura está a exigir uma vigorosa luta na guerra de posições, para a tomada do espaço nas escolas, das agendas públicas, dos espaços acadêmicos, da sistematização e socialização de experiências significativas para travar, com maior intensidade e amplitude, a defesa da escola democrática, popular e voltada aos interesses de crianças, jovens, adultos e idosos, sobretudo daqueles das classes populares.

Em um tempo em que o protofascismo se avizinha, com a emergência de um novo tipo de nacionalismo de extrema-direita, como o percebido na Rússia, na Hungria, na Polônia, na Índia, na Turquia e nos Estados Unidos, como analisa o filósofo Jason Stanley (2018), é preciso estarmos atentos aos sinais e não subestimarmos a ânsia de poder de líderes populistas e autoritários.

Diante de um novo período de gestão pública que se inicia, sob a ascensão de Jair Messias Bolsonaro à presidência da República, é possível afirmar que existem fortes tendências de afirmação de um governo neofascista, militarista, de negação dos direitos humanos, que prima pelo cerceamento ao pensamento crítico, patrulhamento ideológico e censura cultural. Os desdobramentos possíveis dependerão das possibilidades de reação no tecido social mais amplo, assim como da conjuntura internacional.

Trata-se de perceber a centralidade da resistência democrática no país e, no tocante à Educação, do próprio direito das comunidades, educandos e trabalhadores reconstruírem seus fazeres e referências político-pedagógicas, éticas e epistemológicas, e não aceitarem calados as pás de cal que querem jogar os conservadores e neoliberais para definitivamente acabar com a EJA... Nessa direção, referências e vozes como a de Apple (2017) e de Saviani (2018), em torno das tarefas dos intelectuais/ativistas críticos ganham relevância e alcance.

No Brasil, as organizações dos trabalhadores vêm sendo fortemente atacadas e vilipendiadas, com a criminalização e a retirada de direitos. Portanto, não resta qualquer dúvida de que é nossa tarefa afirmar a importância do associativismo, do sindicalismo e dos movimentos dos trabalhadores, de potenciá-los como espaço de luta para a sobrevivência e a reinvenção de sonhos, visões utópicas e experiências de "reformas não reformistas" (APPLE, 20I7). 
Os avanços obtidos do ponto de vista legal em cerca de duas décadas e os marcos de referências que asseguram a EJA como direito só fazem sentido se no cotidiano das comunidades houver o bom combate na defesa da modalidade e, de acordo com o balanço crítico e abalizado de Machado (2016) sobre esse período, há muito a ser feito.

Portanto, a resistência da EJA será tanto mais vigorosa e eficaz na medida em que esteja sintonizada com dois movimentos vigorosos. O primeiro; o do fortalecimento de uma frente de resistência das forças progressistas e populares ao neofascismo e às políticas do Estado mínimo e privatista, que impõe a cultura do silêncio e do medo. O segundo movimento é o de um giro histórico que recoloque em pauta a necessária retomada de um novo ciclo de organização e ascensão dos movimentos sociais e populares, com orientação estratégica à esquerda, que vise o enfrentamento à barbárie e a superação do projeto educativo do capital (MÉSZÁROS, 2005). Mas, para tanto, é preciso, em primeiríssimo lugar, com humildade e autocrítica, fazer um balanço honesto e autocrítico, e reaprender a dialogar com as periferias, da cidade, do campo, da floresta, seus modos de vidas, suas visões de mundo e percepções [...].

\section{Referências}

AB'SÁBER, T. Lulismo, carisma pop e cultura anticrítica. São Paulo: Hedra, 201 I.

ALMEIDA, D. M.; FERREIRA JUNIOR, A. As pesquisas sobre associativismo docente no Brasil: o que dizem as produções acadêmicas nacionais? In: BAUER, C. et alii. (Orgs.). Sindicalismo e Associativismo dos Trabalhadores em Educação no Brasil. Jundiaí-SP: Paco Editorial, 20I5, v. 2, p. 77-89.

ALVES, E.; COMERLATO, D. M.; SANT'ANNA, S. M. L. Mapa da Educação de Jovens e Adultos no Estado do Rio Grande do Sul. Relatório de Pesquisa 2017. Universidade Federal do Rio Grande Do Sul. Faculdade de Educação. Núcleo de Ensino Pesquisa e Educação em Educação de Jovens E Adultos - NIEPE-EJA, 2017. $\overline{\operatorname{Dez} / 2018 .}$

Oferta de vagas e estimativa de demanda pela EJA em Porto Alegre: dados preliminares. Porto Alegre,

AMARAL, N. C. PEC 24I/55: a "morte" do PNE (2014-2024) e o poder de diminuição dos recursos educacionais. Revista Brasileira de Política e Administração da Educação, Goiânia, v. 32, n. 3, p. 653-673, set./dez. 2016.

APPLE, M. W. A luta pela democracia na educação crítica. Revista e-Curriculum, São Paulo, v. 15, n.4, p. 894-926 out./dez. 2017.

ATEMPA - Associação dos Trabalhadores em Educação no município de Porto Alegre. I Encontro de Trabalhadores em Educação. Documento Final, 2013.

Manifesto em defesa da EJA. Porto Alegre, II de dezembro de 2015.

Carta-Manifesto da EJA às autoridades municipais na esfera educacional, conselhos de direitos, parlamentares, órgãos de representação associativa e sindical. SEMINÁRIO DA ATEMPA: A Rede Municipal em Tempos de Resistência: Em defesa da Educação Pública. Porto Alegre, maio de $2017 \mathrm{a}$.

Nota da ATEMPA sobre a EJA de Porto Alegre. Porto Alegre, 10 de agosto de $2017 \mathrm{~b}$.

. Manifestação dos docentes na EJA da RME/POA sobre a jornada de trabalho, reuniões pedagógicas e atendimento aos alunos - base político-pedagógica e legal. Comissão de EJA/ATEMPA. Porto Alegre, 02 de junho de 2017c.

. A educação resiste! A Cidade resiste! Boletim da Resistência n. 2, agosto 2017d.

Boletim da Resistência n. 3. Porto Alegre, março 2018.

Diagnóstico da falta de RH na rede Municipal de Ensino de Porto Alegre: Um retrato do desmonte da Educação Pública. Porto Alegre, 2018a.

. Diante do autoritarismo do secretário de educação, ataque à Atempa vai para a justiça. Porto Alegre. [2018]. Disponível em: http://atempa.org.br/diante-do-autoritarismo-do-secretario-de-educacao-ataque-a-atempa-vai-para-a-justica/ Acesso em: outubro de 20I8b.

A EJA é um direito! A EJA é nossa! Campanha em defesa da EJA em Porto Alegre. ATEMPA, 2018c.

A EJA é um direito! A EJA é nossa! Orientações gerais para as escolas resistirem ao desmonte da EJA. Documento eletrônico. Porto Alegre: ATEMPA, Dez. 2018d. 
BALL, S. J. Educação Global S.A.: Novas redes políticas e imaginário neoliberal. Ponta Grossa: UEPG, 20 I4.

BANCO MUNDIAL. Um ajuste justo: Análise da eficiência e equidade do gasto público no Brasil. Vol. I: Síntese. [S.n.], Novembro de 2017.

COELHO, E. Uma esquerda para o capital: o transformismo dos grupos dirigentes do PT (I979- I998). São Paulo: Xamã, 2012.

CONSELHO MUNICIPAL DE EDUCAÇÃO DE PORTO ALEGRE. Parecer n. 039/20I 7 - Comissão de Ensino Médio, Modalidades e Normas Gerais - CMEd. Ref. a sistemática de matrículas para a EJA, adotada pela SMED no mês de julho de 2017.

DI PIERRO, M. C.; CATELLI JR., R. A construção dos direitos dos jovens e adultos à educação na história brasileira recente. In: GRACIANO, M.; LUGLI R. S. G. (Orgs) Direitos, diversidade, práticas e experiências educativas na Educação de Jovens e Adultos. São Paulo: Alameda, 2017. p.35-60.

FREIRE, P. Pedagogia do oprimido. 12 ed. Rio de Janeiro: Paz e Terra, 1984.

FRIGOTTO, G. A gênese das teses do Escola sem Partido: esfinge e ovo da serpente que ameaçam a sociedade e a educação. In: FRIGOTTO, G. (Org.) Escola “sem” partido: esfinge que ameaça a educação e a sociedade brasileira. Rio de Janeiro: UERJ, LPP, 2017, p. I7-34.

GANDIN, L. A. Escola Cidadã: implementação e recriação da educação crítica em Porto Alegre. In: APPLE, W. M.; AU, W.; GANDIN, L. A. (Orgs.). Educação Crítica: análise internacional. Porto Alegre: Artmed, 20 I I. p. 380-393.

GINDIN, J.; FERREIRA, M. O. V.; DAL ROSSO, S. (Orgs). Associativismo e Sindicalismo em educação: teoria, história e movimentos. Brasília: Paralelo I5, 2013.

GONÇALVES, J.; MELLO, M.; FERREIRA, D. S. As múltiplas escalas geográficas e o desmonte da educação: Uma perspectiva docente sobre o caso de Porto Alegre. III CONGRESSO BRASILEIRO DE GEOGRAFIA POLÍTICA, GEOPOLÍTICA E GESTÃO DO TERRITÓRIO. Rio de Janeiro, 2018.

GRAMSCI, A. Os intelectuais e a organização da cultura. 4 ed. Rio de Janeiro: Civilização Brasileira, 1982.

IASI, M. L. As metamorfoses da consciência de classe (o PT entre a negação e o consentimento). 2 ed. São Paulo: Expressão Popular, 2012.

LEHER, R. Educação no governo de Lula da Silva: a ruptura que não aconteceu. In: MAGALHÃES, J. P. A. et al. (Orgs). Os anos Lula: contribuições para um balanço crítico (2003-20 I0). Rio de Janeiro: Garamond, 20 I0b. p. 369-4I2.

MACHADO, M. M. A educação de jovens e adultos. Após 20 vinte anos da Lei n 9.394, de 1996. Revista Retratos da Escola, Brasília, v. 10, n. 19, p. 429-45I, jul./dez. 2016.

MELLO, M. O espírito, o corpo e o jogo: Intelectuais orgânicos coletivos na ATEMPA (Associação dos Trabalhadores em Educação do Município de Porto Alegre) e suas formulações e ações em torno das Políticas Curriculares da Secretaria Municipal de Educação. (Dissertação). - Mestrado do Programa de Pós-Graduação em Educação. Universidade Federal do Rio Grande do Sul, Porto Alegre, 20I5a.

ATEMPA: história e lutas em torno das políticas curriculares. Revista da ATEMPA. n. I, Out/20I5b.

. Culturas e identidades juvenis na EJA: desafios na formação de educadores. Revista Conhecer. Secretaria Municipal de Educação. Educação de Jovens e Adultos, n.8, Porto Alegre, 20I5c.

MELLO, M. (Org.). Palavras da EJA: Direito do cidadão. Dever do Estado! Porto Alegre: EMEF Saint Hilaire. Educação de Jovens e Adultos, 2018.

MELLO, M.; GONÇALVES, J.; WASZAK, J. (Orgs.). Palavras da EJA: Muitas faces, tantas vozes, outras palavras. Porto Alegre: EMEF Saint Hilaire, Educação de Jovens e Adultos, 2016.

MELLO, M; MAYER, S. S., PAVANI, F. (Orgs) Educação Popular: Crianças, jovens e adultos e o legado de Paulo Freire. Porto Alegre: ATEMPA; Cirkula, 2018. (No prelo).

MÉSZÁROS, I. A educação para além do capital. São Paulo: Boitempo, 2005.

NEWMANN, J.; CLARKE, J. Gerencialismo. Educação e Realidade, Porto Alegre. v. 37, n.2. p.353-38I, mai/ago 2012. PORTO ALEGRE. PREFEITURA MUNICIPAL. Plano de Carreira do Magistério. Lei n 6I5 I/I $988 ., 1996$. 
. SECRETARIA MUNICIPAL DE EDUCAÇÃO. Em busca da Unidade Perdida. Totalidades de Conhecimento: um currículo em Educação Popular. „,Porto Alegre, Set. 1996.

. Plano Municipal de Educação. (20I5-2025). Lei I I.858, de 25 de junho de 2015.

. Convênio SESI - Educação à Distância. Ofício Circular n. 016/2018. Porto Alegre. 3 Out. 2018.

; FÓRUM MUNICIPAL DE EDUCAÇÃO DE PORTO ALEGRE - FME/PoA. Relatório Anual de Monitoramento do Plano Municipal de Educação - PME, Porto Alegre/RS: Nov/20I 7.

SIMPA - SINDICATO DOS MUNICIPÁRIOS DE PORTO ALEGRE. Revista Luta e resistência em defesa do serviço público e da cidade, Porto Alegre: SIMPA, 2017.

. Ano começa com novos ataques aos servidores. Boletim Luta Municipária, n. 42., Fev/20I8.

SINGER, A. Os sentidos do lulismo: reforma gradual e pacto conservador. São Paulo: Companhia das Letras, 2012.

SAVIANI, D. A crise política e o papel da educação na resistência ao golpe de 2016 no Brasil in: KRAWCZYK, N.; LOMBARDI, J. C. (Orgs.). O golpe de 2016 e a educação no Brasil. Uberlândia: Navegando Publicações, 20I8. p.27-46.

STANLEY, J. Como funciona o fascismo: a política do “nós” e “eles”. Porto Alegre: LPM, 2018.

VIERO, A. Educação Popular também se faz na luta: o processo de organização da Comissão da EJA/ATEMPA. In: MELLO, M. (Org.) Paulo Freire e a Educação Popular. Porto Alegre: ATEMPA; IPPOA, 2008. 